\title{
THE INFLUENCE OF CORTISONE AND ADRENOCORTICO- TROPHIC HORMONE ON BRUCELLOSIS. II. ADRENO- CORTICOTROPHIC HORMONE (ACTH) IN ACUTE AND CHRONIC HUMAN BRUCELLOSIS
}

\author{
By WESLEY W. SPINK AND WENDELL H. HALL \\ (From the Department of Medicine of the University of Minnesota Hospitals and Medical \\ School, and the Veterans Administration Hospital, University of Minnesota Medical \\ School, Minneapolis, Minn.)
}

(Submitted for publication April 21, 1952; accepted August 9, 1952)

It has been established that Brucella organisms localize intracellularly within the tissues of animals and human beings $(1-6)$. As pointed out elsewhere $(7,8)$, the majority of patients with brucellosis recover from their illness within a year. While there is no doubt that the duration of the illness in the majority of patients is considerably shortened by the administration of antibiotics, there still remains a small but significant number of patients who continue to have manifestations of active infection after what is considered to be adequate therapy (9). There is evidence that the chronicity of the disease may be due to the continued parasitization of the tissue cells by brucella organisms. Although effective therapeutic agents are available for brucellosis, in vitro investigations have demonstrated that Brucella organisms located in the cytoplasm of the cells of the host are protected against the action of the antibiotics, and also against the antibacterial action of serum (10, $11)$.

In tuberculosis, the invading bacilli tend to localize within the cells of the host, and possibly multiply there (12). Furthermore, it has been demonstrated in tissue cultures that the extracellular organisms of Mycobacterium tuberculosis are readily destroyed by streptomycin, but those bacilli within the macrophages are protected against the lethal action of the drug (13). Hart and Rees (14) have reported that tubercle bacilli are widely disseminated in mice with acute and chronic tuberculosis following the administration of cortisone. Apparently, the dissemination of tubercle

\footnotetext{
1 Reviewed by the Veterans Administration and published with the approval of the Chief Medical Director. The statements and conclusions published by the authors are the result of their own study and do not necessarily reflect the opinion or policy of the Veterans Administration.
}

bacilli from localized areas as a result of treatment with cortisone is not controlled by an extracellular immune mechanism, since the organisms multiply and invade other cells. Abernathy and Spink (15) observed that the administration of cortisone in mice having acute brucellosis results in the dissemination and multiplication of Brucella organisms, and a fulminating and fatal infection ensues. However, in the chronically infected animal, cortisone was without demonstrable effect, probably due in part to an efficient immune mechanism that prevented multiplication of the bacteria and invasion of other cells of the host.

Although experimental and clinical observations have demonstrated quite clearly that the continued illness of both animals and human subjects can be due to the persistence of Brucella organisms in the tissues, it has been difficult to demonstrate the intracellular localization of the Brucella. An analogous situation occurs in rickettsial diseases. It is an accepted fact that the rickettsiae invade the host's tissue cells, but demonstration of the intracellular position of the parasites in human material is often accomplished only after extensive search. Accepting the thesis that Brucella organisms localize and persist intracellularly, ACTH was administered to a group of patients having an acute or chronic illness due to Brucella in the anticipation that the organisms would be released from their intracellular location. It was further anticipated that the extracellular bacteria would be destroyed by bactericidins alone, or with the aid of antibiotic therapy.

Although the primary purpose in administering ACTH to chronically ill patients was to determine if Brucella organisms would be liberated from foci in the body, another objective was to observe the influence of the steroid on the symptomatology that 
frequently persists in patients who have had an acute attack of brucellosis. These subjective manifestations consist of weakness, mental depression, nervousness, anorexia, and vague somatic aches and pains. As discussed elsewhere (7), one cannot always be certain whether these complaints represent the residuals of a previous infection or whether they indicate the presence of a continuing infectious process. There existed the possibility that, whatever the genesis of the symptomatology, the chronically ill patients might not only be temporarily benefited by ACTH, but a better state of health might ensue after its discontinuance.

\section{METHODS OF STUDY}

Seven male patients received ACTH. ${ }^{2}$ Two of the seven patients had acute brucellosis, that is, an illness of less than three months' duration. The remaining five patients had a chronic illness with symptoms enduring for many months. ACTH was administered parenterally in doses of 20 to $25 \mathrm{mg}$. every six hours for seven to 14 days. Just prior to receiving ACTH, several procedures were carried out on the patients as a control on the influence of ACTH. Specimens of venous blood were obtained and added to trypticase-soy broth for cultural purposes. The agglutination test was performed with the serum utilizing the tube-dilution technique and a Brucella abortus antigen supplied by the Bureau of Animal In-

2 Supplied by Armour Laboratories.

TABLE I

Pertinent data of patients with brucellosis given $A C T H$

\begin{tabular}{|c|c|c|c|c|c|c|c|c|c|}
\hline \multirow{3}{*}{$\begin{array}{l}\text { No. } \\
\text { of } \\
\text { pt. }\end{array}$} & \multirow{3}{*}{$\begin{array}{l}\text { Age } \\
\text { and } \\
\text { sex }\end{array}$} & \multirow{3}{*}{$\begin{array}{c}\text { Occupa- } \\
\text { tion }\end{array}$} & \multirow{3}{*}{$\begin{array}{c}\text { Duration } \\
\text { of } \\
\text { symptoms } \\
\text { before } \\
\text { receiving } \\
\text { ACTH }\end{array}$} & \multicolumn{4}{|c|}{ Laboratory data } & \multirow{3}{*}{$\begin{array}{l}\text { ACTH } \\
\text { dose }\end{array}$} & \multirow{3}{*}{ Comment } \\
\hline & & & & \multicolumn{2}{|c|}{ Before ACTH } & \multicolumn{2}{|c|}{$\begin{array}{l}\text { During and after } \\
\text { ACTH }\end{array}$} & & \\
\hline & & & & $\begin{array}{c}\text { Recipro- } \\
\text { cal of } \\
\text { Brucella } \\
\text { titer }\end{array}$ & $\begin{array}{l}\text { Blood } \\
\text { culture }\end{array}$ & $\begin{array}{l}\text { Recipro- } \\
\text { cal of } \\
\text { Brucella } \\
\text { titer }\end{array}$ & $\begin{array}{l}\text { Blood } \\
\text { culture }\end{array}$ & & \\
\hline 1 & $\begin{array}{c}30 \\
\text { Male }\end{array}$ & $\begin{array}{l}\text { Laborer, } \\
\text { meat } \\
\text { packing } \\
\text { plant }\end{array}$ & 6 weeks & 640 & Br. abortus & 640 & $\begin{array}{l}0,0,0,0 \\
0,0,0\end{array}$ & $\begin{array}{l}20 \mathrm{mg} . \\
4 \text { times } \\
\text { daily for } \\
10 \text { days }\end{array}$ & $\begin{array}{l}\text { Improvement; no relapse; good health } 12 \\
\text { months later. }\end{array}$ \\
\hline 2 & $\begin{array}{c}34 \\
\text { Male }\end{array}$ & Farmer & 8 weeks & 1,280 & $\begin{array}{l}\text { Br. abortus } \\
\text { Br. abortus } \\
\text { Br. abortus } \\
\end{array}$ & $\begin{array}{l}1,280 \\
1,280\end{array}$ & $\begin{array}{l}\text { Br. abortus } \\
\text { Br.abortus } \\
\text { Br.abortus } \\
\text { Br.abortus } \\
\text { Br.abortus } \\
\text { Br.abortus } \\
\text { Br.abortus } \\
\text { Br.abortus } \\
\text { Br.abortus } \\
\text { Br.abortus } \\
\text { Br.abortus }\end{array}$ & $\begin{array}{l}25 \text { mg. } \\
4 \text { times } \\
\text { daily for } \\
11 \text { days }\end{array}$ & $\begin{array}{l}\text { Immediate and marked improvement, al- } \\
\text { though blood cultures remained positive. } \\
\text { Subsequent treatment with combined aureo- } \\
\text { mycin and dihydrostreptomycin. Recovery, } \\
\text { and good health for } 3 \text { months. }\end{array}$ \\
\hline 3 & $\begin{array}{c}28 \\
\text { Male }\end{array}$ & Farmer & 9 months & $\begin{array}{r}1,280 \\
1,280 \\
320 \\
160 \\
\pm 160 \\
\end{array}$ & $\begin{array}{l}\text { Br. abortus } \\
\text { Br. abortus } \\
0 \\
0,0,0,0\end{array}$ & \pm 160 & $0,0,0,0$ & $\begin{array}{l}20 \text { mg. } \\
4 \text { times } \\
\text { daily for } \\
\text { one week }\end{array}$ & $\begin{array}{l}\text { Improvement; increase in strength; no relapse; } \\
\text { working } 12 \text { months later. Mild complaints. }\end{array}$ \\
\hline 4 & $\begin{array}{c}54 \\
\text { Male }\end{array}$ & Farmer & 3 months & 640 & $0.0,0$ & 640 & $\begin{array}{l}\mathbf{0}, 0,0,0 \\
0,0,0,0 \\
0,0,0,0 \\
0,0\end{array}$ & $\begin{array}{l}25 \text { mg. } \\
4 \text { times } \\
\text { daily for } \\
10 \text { days } \\
\end{array}$ & $\begin{array}{l}\text { Improvement; relapse of symptoms in } 2 \text { mos. } \\
\text { Had positive serology for syphilis and fracture } \\
\text { of right ankle. }\end{array}$ \\
\hline 5 & $\begin{array}{c}56 \\
\text { Male }\end{array}$ & Farmer & 27 months & $\begin{array}{r}640 \\
2,560 \\
640 \\
\end{array}$ & $\begin{array}{l}\text { Br. abortus } \\
\text { Br. abortus } \\
\mathbf{0}, \mathbf{0}, \mathbf{0}, \mathbf{0}, \mathbf{0} \\
\end{array}$ & $\begin{array}{l}160 \\
320\end{array}$ & $\begin{array}{l}\mathbf{0}, 0,0,0 \\
0,0,0,\end{array}$ & $\begin{array}{l}25 \mathrm{mg} . \\
4 \text { times } \\
\text { daily for } \\
14 \text { days }\end{array}$ & $\begin{array}{l}\text { Improvement; relapse in few days. Given } \\
\text { aureomycin. Working } 12 \text { months later-still } \\
\text { has aches and pains. }\end{array}$ \\
\hline 6 & $\begin{array}{c}35 \\
\text { Male }\end{array}$ & $\begin{array}{l}\text { Electri- } \\
\text { cian, } \\
\text { meat } \\
\text { packing } \\
\text { plant } \\
\\
\end{array}$ & 16 months & $\begin{array}{l}320 \\
640 \\
320 \\
640 \\
320 \\
640 \\
\end{array}$ & $\begin{array}{l}\text { Br. abortus } \\
\text { Br. abortus } \\
0,0\end{array}$ & $\begin{array}{l}1,280 \\
1,280\end{array}$ & $\begin{array}{l}0,0,0,0 \\
0,0,0\end{array}$ & $\begin{array}{l}20 \mathrm{mg} \text {. } \\
4 \text { times } \\
\text { daily for } \\
10 \text { days }\end{array}$ & $\begin{array}{l}\text { Marked improvement; no relapse; good health } \\
\text { for } 9 \text { mos., then entered hospital for sponta- } \\
\text { neous pneumothorax. Recovery. }\end{array}$ \\
\hline 7 & $\begin{array}{c}51 \\
\text { Male }\end{array}$ & Farmer & 9 months & 160 & $0,0,0$ & 160 & 0 & $\begin{array}{l}32.5 \mathrm{mg} \text {. } \\
4 \text { times } \\
\text { daily for } \\
14 \text { days }\end{array}$ & $\begin{array}{l}\text { Patient had destruction of glenoid process of } \\
\text { right shoulder resulting in shoulder-hand syn- } \\
\text { drome and disability. Simultaneous with } \\
\text { ACTH received } 0.5 \text { gm. aureomycin } 4 \text { times } \\
\text { daily for } 3 \text { weeks along with } 0.5 \text { gm. dihydro- } \\
\text { streptomycin twice daily for } 2 \text { weeks. Marked } \\
\text { improvement which has continued for } 3 \text { mos. } \\
\text { since treatment. Now back at work. }\end{array}$ \\
\hline
\end{tabular}




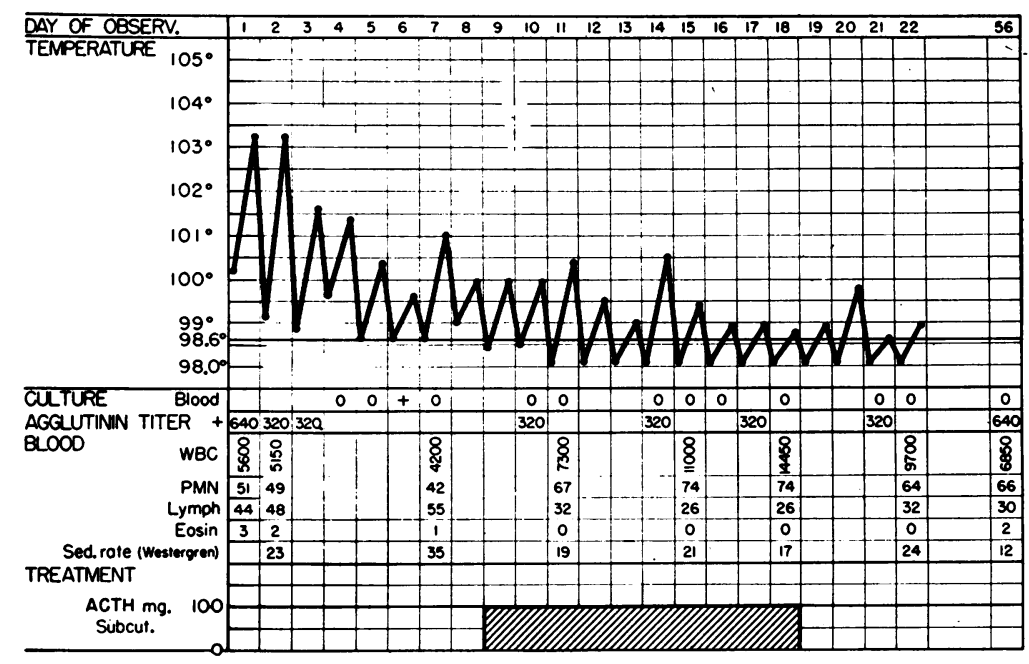

Fig. 1. A. C., 30-Year-Old White Employee of a Meat Packing Plant, TREATED With ACTH

Note positive blood culture due to $\mathrm{Br}$. abortus before receiving $\mathrm{ACTH}$ and sterile cultures during and after administration of ACTH. No relapse within follow-up period of one year.

dustry. Incubation in a water bath at $37^{\circ} \mathrm{C}$. was carried out for 24 to 48 hours. Total leukocyte and differential counts were made. These same procedures were repeated during and after the course of treatment with ACTH. While the patients were receiving $\mathrm{ACTH}$, the influence of the hormone on dermal hypersensitivity to Brucella antigen was determined. The patients were then checked periodically for a minimum of three months, and up to a year, before this report was prepared.

\section{RESULTS}

Pertinent data relating to each patient are presented in Table I with a comprehensive and detailed history in order to eliminate any doubt about the nature of the illness, and to portray the difficult problem of contending with the more chronically ill patients.

\section{ACTH in acute brucellosis}

Case 1. A. C., a 30-year-old white man was admitted to the hospital because of chills, fever, sweats, and weakness of one month's duration. Approximately six months prior to the onset of his illness he had terminated his employment in a meat packing plant, where he was daily exposed to the tissues of cattle condemned for slaughter because of Bang's disease. He had been treated successfully for a brief period with aureomycin. He had a temperature of $103^{\circ} \mathrm{F}$. and a pulse rate of 118 per minute. The only abnormalities noted were slightly enlarged cervical lymph nodes, and bilateral tenderness of the testicles. He had a total leukocyte count of 5,600 cells per cu. mm. with 51 per cent neutrophiles and 44 per cent lymphocytes. The erythrocyte sedimentation rate (Westergren) was $23 \mathrm{~mm}$. in one hour. Brucella agglutinins were present in a titer of 1 to 640 . One of three blood cultures yielded $\mathrm{Br}$. abortus.

After a brief period of observation at bed rest the patient was given $25 \mathrm{mg}$. of ACTH subcutaneously four times daily for 10 days. A graphic presentation of his clinical course is shown in Figure 1. While he was receiving ACTH there was no abrupt subjective or objective change in the condition of the patient. The temperature declined by lysis. Five specimens of venous blood taken during the period of $\mathrm{ACTH}$ administration and two obtained after the injections were discontinued remained sterile. ACTH did not induce any significant changes in the agglutinin titer. One interesting laboratory finding was an increase in the leukocyte count to 14,450 cells during ACTH therapy, with 76 per cent neutrophiles and 26 per cent lymphocytes. This is an unusual observation during the course of acute brucellosis. The erythrocyte sedimentation remained essentially unchanged. During thirty days after the conclusion of the injections of $\mathrm{ACTH}$, he remained well and afebrile. There were no abnormal physical findings. The titer of Brucella agglutinins was 1 to 640 , and three specimens of venous blood obtained on three consecutive days remained sterile. In the year following the administration of $\mathrm{ACTH}$ he had not had a relapse.

Comment: Contrary to expectations, a febrile patient with acute brucellosis and a bacteremia due to $\mathrm{Br}$. abortus recovered from his illness following the administration of ACTH. The only apparent significant hematologic influence of ACTH was 
an increase in the total leukocyte count and a diminution in the number of lymphocytes and eosinophile cells.

Case 2. W. J. K., a 34-year-old white tenant farmer had the onset of an illness eight weeks prior to entering the hospital. The initial manifestations were chills and a fever of $104^{\circ} \mathrm{F}$. He took aureomycin for a brief period of time, and he became afebrile; but he continued to feel weak and he had a relapse of chills and fever. $\mathrm{He}$ then received aureomycin and penicillin, and concomitantly his temperature became normal, but after several days there was a recurrence of daily chills and fever. Until he presented himself for his final hospital admission in Minneapolis the diagnosis of brucellosis had not been established. He worked with a large herd of high-grade dairy cattle, and although there had not been any abortions in the herd for three years, he had assisted the local veterinarian in vaccinating the calves twice yearly with a viable culture of strain $19 \mathrm{Br}$. abortus. The herd had not been tested recently for Bang's disease.

$\mathrm{He}$ appeared quite toxic with a temperature of $101.4^{\circ} \mathrm{F}$. There were no abnormal physical findings other than the edge of a tender liver $4 \mathrm{cms}$. below the costal margin. Jaundice was not present. Prior to the administration of ACTH the total leukocyte count was 5,000 per cu. mm. with 52 per cent neutrophiles and 46 per cent lymphocytes. The erythrocyte sedimentation rate of $15 \mathrm{~mm}$. in one hour was within normal limits. Brucella agglutinins were present in a titer of 1 to 1,280 . Br. abortus was cul- tured from four specimens of venous blopd obtained on consecutive days. Liver function studies showed 10 per cent bromsulfalein retention, normal serum bilirubin, normal prothrombin time, $2+$ cephalin flocculation, thymol turbidity of 7.6 units and zinc sulfate turbidity of 12.9 units. Stained sections of sternal bone marrow aspirated on the day treatment with ACTH was begun revealed multiple granulomas. A section of liver acquired on the same day showed localized areas of lymphocytes, epithelioid cells, and fibroblasts characteristic of granulomatous inflammation.

After the patient had been observed in bed for a few days, ACTH was administered in a dose of $25 \mathrm{mg}$. intramuscularly every six hours for 11 days. The course of events is presented graphically in Figure 2. Within 15 hours after the first injection of ACTH his temperature returned to normal and was never above $100^{\circ} \mathrm{F}$. during hormone treatment. By the fourth day he felt much improved. At this time the liver was notably smaller and the tenderness had abated. $\mathrm{He}$ was ambulatory on the seventh day. The following day a skin test with a carbohydrate fraction of Brucella induced a very slight reaction. The leukocyte count rose from 3,600 to 7,600 with 82 per cent neutrophiles. The erythrocyte sedimentation rate remained within normal limits. The titer of Brucella agglutinins was the same. But cultures of the blood continued to show the presence of Br. abortus (Figure 2). Liver function tests remained essentially unchanged. Sections of the liver obtained at the conclusion of 10 days' ACTH administration showed approxi-

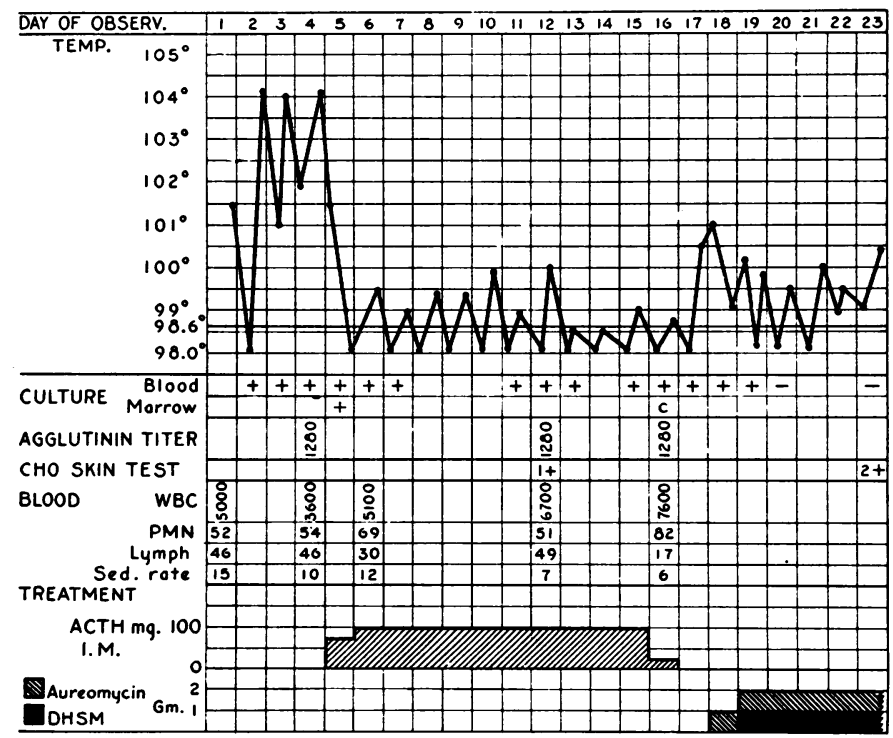

Fig. 2. Case 3. W. J. K., a 34-Year-Old Farmer Treated with ACTH

Note the drop in temperature coincident with administration of ACTH, and persistence of bacteremia due to $\mathrm{Br}$. abortus. Treated subsequently and successfully with aureomycin and dihydrostreptomycin. 


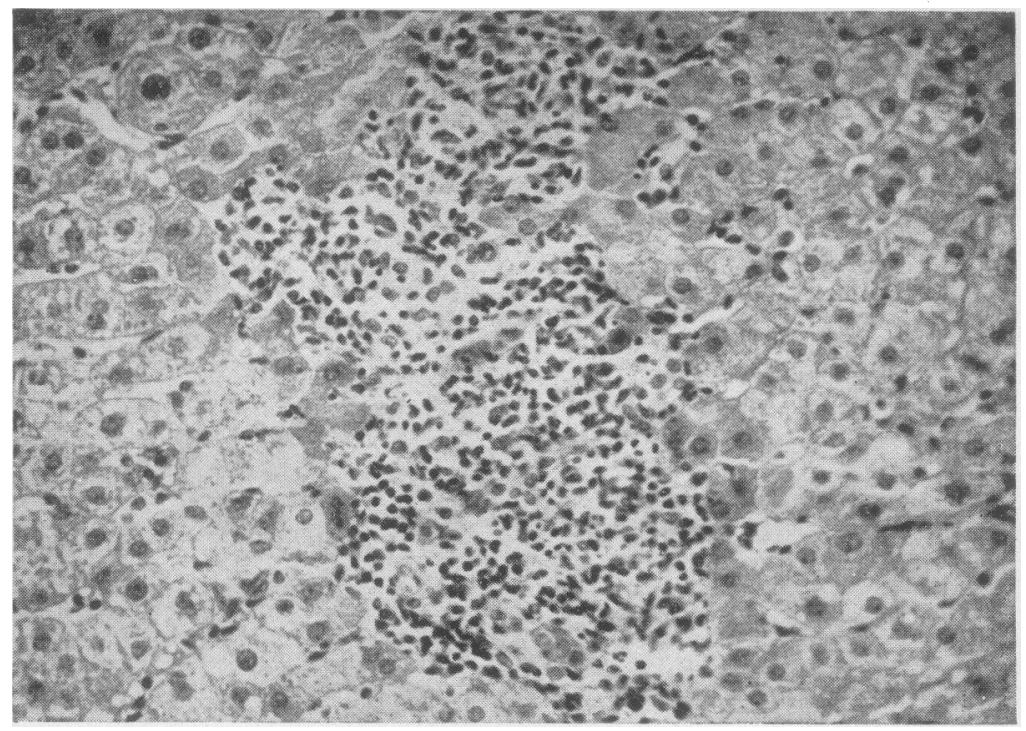

Fig. 3. Specimen of Liver from Case 2 Showing a Granuloma Obtained Before the Administration of ACTH

Hematoxylin and eosin. $350 \times$.

mately the same type and extent of cellular reaction as did those just prior to the beginning of treatment (Figures 3 and 4 ). Likewise, sections of sternal bone marrow revealed the same appearance of granulomas before and after treatment. On the day that ACTH was discontinued the patient had no complaints. No physical abnormalities could be demonstrated. Because of the persistent bacteremia and a slight elevation of temperature, simultaneous treatment with aureomycin and dihydrostreptomycin was instituted. He received $0.5 \mathrm{gm}$. of aureomycin orally every six hours for three weeks. Dihydrostreptomycin was administered intramuscularly in a dose of $0.5 \mathrm{gm}$. every 12 hours for two weeks. Shortly after this com bined treatment was started the bacteremia was eradicated. He continued to feel well and has had no further re'apses three months after the conclusion of treatment.

Comment: The most striking feature was the abrupt improvement that occurred within 24 hours after the first injection of ACTH. A toxic and listless patient became alert and afebrile. The remarkable aspect is that such a state of well-being persisted although Brucella organisms still could be cultured from the blood. Another interesting observation was the decrease in the size and tenderness of the liver induced by ACTH, although there was no essential change in the inflammatory reaction. As in Case 1, ACTH influenced the leukocytes in the peripheral blood with a shift from a relative lymphocytosis to an increase in the polymorphonuclear cells and an elevation in the total leukocyte count.

\section{ACTH in chronic brucellosis}

Case 3. G. M:, a 28-year-old white farmer had had an acute illness of two weeks' duration with chills, sweats, nausea and vomiting. Because of a duodenal ulcer he had ingested large amounts of unpasteurized milk. $\mathrm{He}$ did

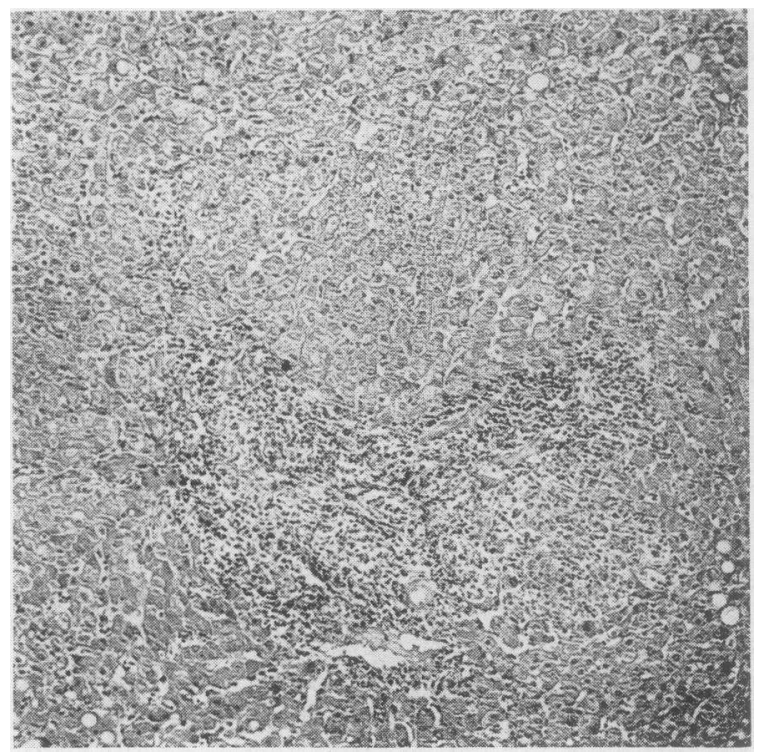

Fig. 4. Specimen of Liver Obtained from Case 2 after ACTH Had Been Administered for 11 Days

A granuloma is demonstrated. There was no essential change in the histology of the liver. Hematoxylin and eosin. $100 \times$. 
not know of any Bang's disease in his herd of cattle, but his neighbor's cattle in an adjoining pasture had the disease. His temperature was $104^{\circ} \mathrm{F}$., and he had lymphadenopathy, hepatomegaly, and an enlarged and tender spleen. The titer of Brucella agglutinins was 1 to 1,280 , and $\mathrm{Br}$. abortus organisms were isolated from the blood on two occasions. He was given aureomycin, and then terramycin, after which his symptoms subsided. The spleen was still palpable at the costal margin. Three cultures of blood taken on consecutive days remained sterile, and the titer of agglutinins was 1 to 1,280 . A month later he was still without symptoms and afebrile, but the spleen was just palpable. Brucella agglutinins were present in a titer of 1 to 320 , and a blood culture remained sterile. Six months later he complained of weakness. $\mathrm{He}$ was afebrile, and the spleen could not be felt. Two blood cultures remained sterile, and the titer of agglutinins was 1 to 160 .

$\mathrm{He}$ was readmitted to the hospital nine months after his initial hospitalization because he tired easily. He admitted using alcohol excessively. He was afebrile. The spleen was not palpable. The total leukocyte count was 7,000 with 72 per cent neutrophiles and 19 per cent lymphocytes. The erythrocyte sedimentation rate was normal. An agglutination test showed incomplete clumping of the brucella antigen up to a titer of 1 to 160 . Two other agglutination tests revealed no agglutinins in his serum. Daily cultures of blood for three days remained sterile. He was given $20 \mathrm{mg}$. of ACTH subcutaneously four times daily for one week. During this time the patient felt stronger, but there were no objective changes noted. There were no alterations of the leukocyte counts or of the sedimentation rate. On the sixth day of therapy with ACTH there was no immediate skin reaction following the intradermal injection of $0.1 \mathrm{ml}$. of a 1 to 100 dilution of Brucella carbohydrate, and 24 hours later only a moderate reaction was seen. A skin test with heat-killed Brucella cells also showed a moderate reaction of the delayed type. After 15 days of hospitalization he was discharged. He felt well. When examined three months later he still felt well. At this time the antigen was only partially agglutinated by his serum in a titer of 1 to 160 , and two blood cultures remained sterile. He has continued in good health for a year.

Comment: This was the first patient with presumed chronic brucellosis who was treated with ACTH. Although there is no doubt that he had acute brucellosis, there is some question as to whether a chronic infection was responsible for his ill health at a later time. He felt weak, but he was an alcoholic. He had a declining titer of Brucella agglutinins, and the test showed incomplete clumping of the antigen, which is so characteristic of the serum of those patients who have recovered from brucellosis. It is of interest that ACTH dimin- ished but did not abolish the delayed type of dermal hypersensitivity to Brucella antigens.

Case 4. A. H., a 54-year-old white farm worker who had chills, fever, sweats, headaches, weakness, and epigastric distress about three months before entry into the hospital. Shortly before, he had fractured his ankle. At the time he became ill he worked on a farm where he drank unpasteurized milk and a cow had aborted. His temperature was normal. The only observed abnormality was a swollen and stiffened right ankle. The total leukocyte count was 8,600 with 56 per cent neutrophiles and 42 per cent lymphocytes. The erythrocyte sedimentation rate was $26 \mathrm{~mm}$. in one hour and Brucella agglutinins were present in a titer of 1 to 640 . Three cultures of blood taken on consecutive days remained sterile.

He was given $25 \mathrm{mg}$. of ACTH subcutaneously four times daily for ten days. Coincident with this he remained afebrile, felt well and gained nine pounds. There was no pitting edema, but after the injections of ACTH were discontinued, a diuresis occurred and he lost all the gain in weight. There was no significant change in the titer of agglutinins. Ten cultures of blood taken during and after ACTH treatment remained sterile. His leukocyte count rose to 11,500 with 84 per cent neutrophiles and 15 per cent lymphocytes. The sedimentation rate declined to $8 \mathrm{~mm}$. in an hour. He felt well when he left the hospital 18 days after entry. About six weeks later he returned complaining of weakness and epigastric distress. He was afebrile and there was evidence of a poorly uniting fracture of the ankle. The titer of Brucella agglutinins was 1 to 640 . Five cultures of blood remained sterile. Serologic tests for syphilis were positive and he admitted having had a primary infection 25 years previously treated with two long courses of injections. The cerebrospinal fluid was normal. A few days after this second appearance at the hospital he had evidence of a pulmonary infarction with a slight pleural effusion. Following rest in bed and treatment with aureomycin and penicillin he left the hospital feeling well. He was fitted with a brace to aid in the healing of the fracture. He has had no further relapse.

Comment: It is very likely that this patient had had an attack of acute brucellosis, and the evidence favored a continuation of the disease when he was seen at the hospital three months after the onset. The ACTH did not appear to alter his clinical course significantly.

Case 5. L. J. L., a 56-year-old white farmer had been ill for two years before his first appearance with chills, fever, sweats, dizziness, weakness and headaches. He drank unpasteurized milk and one of his cows had aborted. He appeared chronically ill with a temperature of $100.2^{\circ} \mathrm{F}$. There were no demonstrable physical abnormalities. The total leukocyte count was 3,700 with 60 per cent neutrophiles and 32 per cent lymphocytes. The erythrocyte sedimentation rate was $57 \mathrm{~mm}$. in one hour. The 
titer of Brucella agglutinins was 1 to 640 , and $B r$. abortus organisms were isolated from two cultures of blood. He was given $0.5 \mathrm{gm}$. of aureomycin orally every six hours for 21 days. He became afebrile and symptomatic, and the titer of Brucella agglutinins was 1 to 2,560.

$\mathrm{He}$ returned three months later feeling better than on his previous entry, but he still had a low-grade fever, cough, diarrhea, and became fatigued readily following physical exertion. He was afebrile and there were no unusual physical abnormalities. The leukocyte count was 5,500 with 64 per cent neutrophiles and 28 per cent lymphocytes. The erythrocyte sedimentation rate was $40 \mathrm{~mm}$. in one hour and the titer of Brucella agglutinins 1 to 640 . $\mathrm{Six}$ cultures of blood remained sterile. $\mathrm{He}$ was then given $25 \mathrm{mg}$. of ACTH subcutaneously four times daily for 14 days. During this time he developed a mild euphoria. His temperature remained normal. Prior to receiving ACTH he had a mild tremor of his hands, which felt cold and clammy. These manifestations diminished during the course of ACTH. There was no change in the titer of agglutinins, and nine cultures of blood observed during and after the administration of ACTH remained sterile. The patient stated that shortly after the injections of ACTH had been discontinued, and while he was at home, he developed severe weakness and marked tremor of the hands. His temperature rose to $99.6^{\circ} \mathrm{F}$. A month later he returned. There were no abnormal physical findings. The titer of Brucella agglutinins was 1 to 160 . Two cultures of blood remained sterile. $\mathrm{He}$ was then treated simultaneously for 12 days with $0.5 \mathrm{gm}$. of aureomycin every six hours and $0.5 \mathrm{gm}$. dihydrostreptomycin given intramuscularly twice daily. Treatment was discontinued because of the appearance of weakness, anorexia, and a display of hostility. An elevation of eosinophile cells to 12 per cent occurred. His behavior was thought to be an unusual type of reaction to the treatment, because as soon as the drugs were withheld the symptoms abated and the eosinophilia disappeared. His Brucella agglutinins showed a titer of 1 to 320, and nine cultures of blood remained sterile during and after treatment. $\mathrm{He}$ remained afebrile up to three months later. The titer of agglutinins was 1 to 80 , and a blood culture was sterile.

Comment: This represented an unusual case of chronic brucellosis in our experience, since the patient had been ill for two years without any localizing manifestations and at the end of this time $\mathrm{Br}$. abortus was cultured from his blood. He appeared to improve following treatment with aureomycin. His blood cultures remained sterile, although many specimens were studied. It was concluded that he still had active disease just prior to his receiving ACTH. Temporary improvement occurred while ACTH was being administered but the manifestations of an active disease appeared shortly thereafter. He apparently responded satisfactorily to treatment with aureomycin and dihydrostreptomycin.

Case 6. A. J., a 35-year-old white electrician employed in a meat packing plant first became ill with joint pains, nocturnal sweats, chills, cold feet, and fatigue. After two months of continued illness he was sent to a hospital for pulmonary tuberculosis because an X-ray film of the chest revealed a diffuse infiltration. Extensive studies eliminated tuberculosis. Although only a low-grade fever was present, $B r$. abortus was isolated from blood cultures on two occasions. He was given $2 \mathrm{gm}$. of chloramphenicol daily for 10 days and felt better. It was concluded that the pulmonary changes were unrelated to his brucellosis. A film of the chest taken some time before the onset of his illness had revealed lesions in the lungs. It was brought out on questioning that as an electrician he had broken fluorescent light tubes on many occasions, and berrylium intoxication was considered but never proven as the cause of the findings in the lung. $\mathrm{He}$ continued well until seven months after his discharge from the hospital when he suffered from pain in the chest, sweats, nervousness, backache and fatigue. Although blood cultures remained sterile, Brucella agglutinins were present in a titer of 1 to 640 . He was given $0.5 \mathrm{gm}$. of aureomycin four times daily for two weeks after which he felt improved.

Four months later, or 16 months after the onset of his illness, he presented himself again because of nervousness, weakness, and sweats. It was decided to administer ACTH. $\mathrm{He}$ was afebrile and no abnormal physical findings could be detected. The leukocyte count was 6,850 with 81 per cent neutrophiles and 16 per cent lymphocytes. The sedimentation rate was normal. The titer of brucella agglutinins was 1 to 640 and a culture of blood remained sterile. He was given $20 \mathrm{mg}$. of ACTH subcutaneously every six hours for 10 days. A remarkable change took place in this patient within 24 hours. His mental depression subsided and his appetite increased considerably. The patient stated that he felt better than he had for many months. On the fifth day an intradermal test with brucellergen revealed a very slight reaction in 24 hours. The agglutinin titer was 1 to 1,280 , and seven cultures of blood during and after the administration of ACTH remained sterile. Fifteen hours after the injections of ACTH had been discontinued the patient experienced excrutiating pains in both knees with radiation to a point between the knees and ankles. Morphine was necessary to allay the pain. There was no redness or swelling of the extremities. Within four days the pain had completely subsided. The patient went back to work and was well until nine months later when he had a spontaneous pneumothorax. After a brief period of hospitalization the lung re-expanded. At this time his Brucella agglutinins were 1 to 640 , and blood cultures were sterile. He returned to work.

Comment: Of all the patients with chronic brucellosis who received ACTH this patient experi- 
enced the greatest benefit. His illness was complicated by a diffuse pulmonary infiltration of doubtful etiology, which was probably unrelated to his brucellosis, and not benefitted by ACTH.

Case 7. H. J., a 51-year-old white farmer nine months prior to being studied had had a sore throat, pain in both shoulders, and bilateral orchitis. He had been treated with an antibiotic which was followed by partial relief of his symptoms. Two months later he had a "kidney infection" and then he developed a severe pain in his right shoulder. Subsequently the pain extended down the arm and involved the right hand so that his fingers became stiffened and movement was painful. He was incapacitated from working as a farmer. He had a herd of 31 cattle in which abortions had occurred, but no tests for Bang's disease had been made. He was afebrile. There was muscular atrophy in the region of the right shoulder, and pressure over the acromial area elicited pain. The fingers of the right hand were swollen and flexion was impaired. The right arm could not be elevated above the level of the shoulder. The white blood count was 7,700 with 64 per cent neutrophiles and 24 per cent lymphocytes. The sedimentation rate was normal. The brucella agglutinin titer was 1 to 160 , and blood cultures remained sterile. An X-ray film of the right shoulder revealed marked decalcification of the right humerus, especially the head. In addition, there was decalcification of the glenoid process and evidence of destruction along one margin of the rim of the glenoid.

$\mathrm{He}$ was treated simultaneously with dihydrostreptomycin, aureomycin and ACTH. He was given $0.5 \mathrm{gm}$. of dihydrostreptomycin intramuscularly twice daily and $0.5 \mathrm{gm}$. of aureomycin orally every six hours for two weeks. At the same time he received $32.5 \mathrm{mg}$. of ACTH intramuscularly every six hours for two weeks. Therapy with aureomycin alone was continued another week. Physiotherapeutic measures for the right arm were also instituted. Under this regimen there was gradual improvement. There was no change in his agglutinin titer and a blood culture remained sterile. When seen two months after the completion of his treatment, he was back at work. There had been continued improvement, but there still was some limitation in movement of the right arm.

Comment: This patient was considered to have had a severe attack of acute brucellosis nine months prior to receiving treatment with ACTH. The severity of his illness was evidenced by the presence of bilateral orchitis and a destructive lesion of the joint of the right shoulder. He had received antibiotic therapy in amounts sufficient to control the infection partially, but not enough to prevent the appearance of an unusual manifestation of brucellosis, that of a shoulder-hand syndrome. Because of the destructive lesion of a joint it was deemed inadvisable to administer ACTH without affording the patient protection with an antibacterial agent or agents. ACTH appeared to be desirable therapeutically in view of the stiffened fingers of the right hand. For these reasons, antibacterial drugs and ACTH were administered simultaneously, and coincident with this therapeutic approach there was definite improvement in the condition of the patient. His health was restored enough to permit him to resume work.

\section{DISCUSSION}

The most striking effects of ACTH in human brucellosis were elicited in those patients who had had symptoms for less than three months (Cases 1 and 2). Both of these patients had a demonstrable bacteremia due to $\mathrm{Br}$. abortus just prior to the administration of ACTH. The hormone did not have any deleterious effect on the clinical course of either patient. While no abrupt change was noted in Case 1, the patient did improve and there was no further evidence of bacteremia after the injections of ACTH were instituted. This patient did not suffer from any ill effects after the injections were discontinued, and he has remained well for 12 months. The sequence of events occurring in Case 2 as a result of ACTH may shed further light on the basic mechanisms of disease in brucellosis. In the first place, a febrile patient having a very toxic appearance was converted into an afebrile individual having the appearance and feeling of decided improvement within 24 hours after the initial injection of ACTH. Although therapy with the antibiotics will provoke such improvement, the changes have not been so abrupt nor have they occurred so quickly (9). This immediate improvement manifested itself in Case 2 although $\mathrm{Br}$. abortus could readily be cultured from the blood. Similar responses have been observed in patients with pneumococcic infections and those with typhoid fever treated with ACTH or cortisone (16-18). Besides the clinical improvement displayed by Case 2 , there were other objective changes that occurred in both Cases 1 and 2. A very common laboratory finding in patients with active brucellosis is a normal leukocyte count, or a leukopenia, with a relative lymphocytosis. During the administration of ACTH in Case 1 the leukocyte count rose to 14,450 , a level which is 
rarely seen in brucellosis and there was an increase in the polymorphonuclear cells with a relative decline of the lymphocytes. Similarly, in Case 2 there was rise in the leukocyte count, an increase in the number of neutrophile cells and a relative depression of the lymphocytes. ACTH did not appear to alter the titer of Brucella agglutinins, but dermal sensitivity to Brucella antigen was suppressed in Case 2.

Another provocative series of observations made in Case 2 related to the tissue reactions induced by Brucella and the influence of ACTH upon these reactions. It is to be recalled that in Case 2, prior to the administration of ACTH, the liver was enlarged and tender, and the results of liver function studies were abnormal. In addition, a specimen of liver showed the presence of hepatitis, which is a common finding in human brucellosis (19). Likewise, aspirated sternal bone marrow showed the characteristic granulomatous type of inflammation (20). It was anticipated that the administration of ACTH might intensify these inflammatory reactions, but on the contrary, the tenderness and enlargement of the liver decreased shortly after the injections were begun, and specimens of liver and bone marrow examined after the completion of the injections of ACTH did not reveal any essential change. During the course of ACTH administration there were no alterations in the functional studies of the liver as compared to the studies carried out just before the start of $\mathrm{ACTH}$ administration.

The abrupt clinical improvement manifested by Case 2 without eradication of the bacteremia and without any change in the inflammatory reaction of the tissue suggested that ACTH inhibited the toxic action of a product or products (? endotoxin) of Brucella upon the body. It has been observed in this laboratory that the simultaneous administration of cortisone will protect mice against the lethal effect of Brucella endotoxin (21).

The observations on experimental brucellosis in animals, especially in mice, which preceded these in human brucellosis, revealed that if animals were pretreated with cortisone and then infected with Brucella organisms, a fulminating and lethal infection ensued (15). Specimens of the liver showed necrosis of the hepatic cells and tremendous numbers of Brucella organisms invading the parenchymal cells and engorging the macrophages in the liver sinusoids. In the control animals that had not received cortisone, the infection was relatively mild, the inflammatory reaction was of the granulomatous type with little or no necrosis, and proliferation of the bacterial cells not marked. No such a sequence of events was observed in the human cases of acute brucellosis treated with ACTH. Perhaps the essential difference is not that the animals received cortisone and the humans $\mathrm{ACTH}$, but rather that cortisone was offered to the infected animals before any immune response to the infection had been established, whereas the human patients had been ill for a period of time sufficient to permit the development of an effective antibacterial mechanism. While much remains to be learned about tissue and humoral immunity in brucellosis, the observations in the chronically infected animals and human beings indicate that the immune mechanism is efficient enough to prevent a dissemination of the infection when cortisone or ACTH is administered. This is contrary to observations made in experimental and human tuberculosis $(14,22,23)$.

The administration of $\mathrm{ACTH}$ to patients having chronic brucellosis appeared to have little effect on the course of the illness except in one or two instances. Patient 7 was in a depressed mental state prior to receiving the hormone, but during its administration he experienced a feeling of well-being that endured for several months after the injections had been discontinued. ACTH did not have any undesirable effects on any of the five patients with chronic brucellosis. The hormone did suppress the dermal hypersensitivity to Brucella antigen, but it did not significantly alter the titer of Brucella agglutinins. In no instance, did Brucella organisms appear in cultures of blood during and after the administration of ACTH. It was anticipated that the administration of ACTH to patients with chronic brucellosis might liberate Brucella organisms from their foci and a bacteremia might be demonstrated. Failure to elicit this result might be related to the relatively small number of bacteria released, and to a humoral immunity effectively destroying the organisms as they appeared in the blood.

Upon the basis of the present observations, and because therapy with the antibiotics is so effective in the majority of patients, there is little or no indication for using either cortisone or ACTH in the 
treatment of human brucellosis. A further contraindication is the undesirable side effects induced by these agents. The one possible indication for the use of either cortisone or ACTH would be in a seriously ill and toxic patient. Even in such a case, treatment probably should be carried out only for a day or two, and simultaneous treatment should be started with streptomycin or dihydrostreptomycin, in combination with aureomycin or terramycin. A similar approach has been made in the treatment of typhoid fever $(16,17)$.

The present results with ACTH in acute brucellosis have stimulated a further consideration of the mechanism whereby patients appear to benefit following the intravenous injection of Brucella antigens. Such authorities as Janbon (24) in Montpellier, France; Signorelli (25) in Farrar, Italy; and Huddleson (26) in this country have called attention to the beneficial results that have occurred in patients with acute and chronic brucellosis following the intravenous injection of Brucella antigens. It is of interest that improvement in the patient's condition is usually associated with a febrile reaction and, at times, a shocklike picture with a drop in blood pressure. Although it is often asserted that the Brucella preparations are specific in their beneficial action, some doubt has been cast upon this conclusion by the observations of Löffler and his associates (27), who obtained equally good results following the injection of suspensions of colloidal silver. It might be postulated that the febrile reaction induced by these agents provoked a stress reaction which in turn stimulated the adrenals to produce corticosteroids with the results as presented in Cases 1 and 2. Another possibility is that the febrile reaction with its mild shock-like manifestations might be representative of a generalized Shwartzman reaction in which Brucella organisms are liberated from localized foci, and disposed of by an extracellular immune mechanism. Further studies along these lines are in progress at the present time.

\section{SUMMARY}

1. Adrenocorticotrophic hormone (ACTH) was administered to two patients with acute brucellosis and to five patients with chronic disease. The administration of ACTH to one of the patients with acute brucellosis, who was quite ill, was accompanied by a prompt and remarkable improvement although the blood cultures remained positive for $\mathrm{Br}$. abortus. ACTH did not appear to have any significant effect on the clinical course of chronic brucellosis.

2. Specimens of liver and sternal bone marrow from one patient with acute brucellosis displaying granulomas showed no essential change in the type or degree of inflammation before and after the administration of ACTH.

3. ACTH had no significant effect upon the titer of Brucella agglutinins, but it did suppress dermal hypersensitivity to Brucella antigens. The tendency of Brucella organisms to cause a leukopenia and relative lymphocytosis was abolished by ACTH.

4. The only therapeutic indication for cortisone or ACTH at the present time in acute or chronic brucellosis is in patients who are quite ill and toxic. And even then, treatment should be carried out for only a few days and simultaneously with antibiotic therapy.

\section{REFERENCES}

1. Fabyan, M., A contribution to the pathogenesis of $B$. abortus, Bang. II. J. Med. Research, 1912, 26, 441.

2. Smith, T., A characteristic localization of Bacillus abortus in the bovine fetal membrane. J. Exper. Med., 1919, 29, 451.

3. Goodpasture, E. W., and Anderson, K., The problem of infection as presented by bacterial invasion of the chorio-allantoic membrane of chick embryos. Am. J. Path., 1937, 13, 149.

4. Meyer, K. F., Observations on the pathogenesis of undulant fever, in Essays in Biology, University of California Press, San Francisco, 1943, pp. 439452.

5. Castaneda, M. Ruiz-, Studies on the pathogenesis of brucellosis. Proc. Soc. Exper. Biol. \& Med., 1947, 64, 298.

6. Braude, A. I., Studies in the pathology and pathogenesis of experimental brucellosis. II. The formation of the hepatic granuloma and its evolution. J. Infect. Dis., 1951, 89, 87.

7. Spink, W. W., What is chronic brucellosis? Ann. Int. Med., 1951, 35, 358.

8. Spink, W. W., and Magoffin, R. L., Clinical Course of Human Brucellosis in Minnesota, in Proc. Third Inter-American Congress on Brucellosis, Pan American Sanitary Bureau, Washington, D. C., 1950, p. 94.

9. Spink, W. W., Hall, W. H., and Magoffin, R., Follow-up study of therapy in forty-eight culturally proved cases of brucellosis. Streptomycin and 
sulfadiazine, aureomycin, and chloramphenicol (Chloromycetin(\$). Arch. Int. Med., 1951, 88, 419.

10. Magoffin, R. L., and Spink, W. W., The protection of intracellular brucella against streptomycin alone and in combination with other antibiotics. J. Lab. \& Clin. Med., 1951, 37, 924.

11. Shaffer, J. M., and Kucera, C. J., Studies on the biologic significance of the protection afforded intracellular brucella. J. Clin. Invest., 1952, 31, 661.

12. Rich, A. R., The Pathogenesis of Tuberculosis, Charles C. Thomas, Springfield, Ill., 1952, Second Edition, Chap. 4 and 8.

13. Barski, G., Action de la streptomycine sur l'infection tuberculeuse en cultures de tissus. Ann. de l'Inst. Pasteur, 1948, 74, 1.

14. Hart, P. D., and Rees, R. J. W., Enhancing effect of cortisone on tuberculosis in the mouse. Lancet, 1950, 2, 391.

15. Abernathy, R., and Spink, W. W., The influence of cortisone and adrenocorticotrophic hormone on brucellosis. I. Cortisone in experimentally infected animals. J. Clin. Invest., 1952, 31, 947.

16. Smadel, J. E., Treatment of typhoid fever. I. Combined therapy with cortisone and chloramphenicol. Ann. Int. Med., 1951, 34, 1.

17. Woodward, T. E., Hall, H. E., Dias-Rivera, R., Hightower, J. A., Martinez, E., and Parker, R. T., Treatment of typhoid fever. II. Control of clinical manifestations with cortisone. Ann. Int. Med., 1951, 34, 10.

18. Kass, E. H., Ingbar, S. H., and Finland, M., Effects of adrenocorticotropic hormone in pneumonia: Clinical, bacteriological and serological studies. Ann. Int. Med., 1950, 33, 1081.
19. Spink, W. W., Hoffbauer, F. W., Walker, W. W. and Green, R. A., Histopathology of the liver in human brucellosis. J. Lab. \& Clin. Med., 1949, 34, 40.

20. Sundberg, R. D., and Spink, W. W., The histopathology of lesions in the bone marrow of patients having active brucellosis. Blood, Supp. No. I, 1947, p. 7.

21. Anderson, D., and Spink, W. W., The protection of mice with cortisone against the lethal effect of brucella lipo-protein. To be published.

22. Fred, L., Levin, M. H., Rivo, J. B., and Barrett, T. F., Development of active pulmonary tuberculosis during ACTH and cortisone therapy. J. A. M. A., 1951, 147, 242.

23. LeMaistre, C. A., Tomsett, R., Muschenheim, C., Moore, J. A., and McDermott, W., Effects of adrenocorticotropic hormone and cortisone in patients with tuberculosis. J. Clin. Invest., 1951, 30, 445.

24. Janbon, M., Encyclopédie Médico-Chirurgicale: Maladies Infectieuses. Edited by Debré, R. and Aubry, G., Paris, 1951, $8038 \mathrm{Ba}$, p. 1.

25. Signorelli, S., L'Infezione Brucellare Nell'Uomo, Second Edition, Casa Editrice Libraria V. Idelson, Naples, 1949, Chapter XVIII.

26. Huddleson, I. F., and Johnson, H. W., "Brucellin," a possible specific for undulant fever in man. Am. J. Trop. Med., 1933, 13, 485.

27. Löffler, W., Moeschlin, S., and Willa, A., Klinik und pathologie der febris undulans bang unter besonderer berücksichtigung der spezifischen komplikationen (an hand von 150 eigenen fällen), Ergebnisse der Inneren Medizin und Kinderheilkunde, 1943, 63, 714. 